\title{
A Novel Digital Platform Approach to Enhance Enterprise-Wide Patient Portal Adoption
}

Yauheni Solad ${ }^{1}$, MD, MHS; Shrawan Patel $^{2}$, MBBS, BSc (Hons); Allen Hsiao ${ }^{3}$, FAAP, MD; Ashish Atreja ${ }^{2}$, MD, $\mathrm{MPH}$

\footnotetext{
${ }^{1}$ Yale New Haven Health, Digital Health, Stratford, CT, United States

${ }^{2}$ Icahn School of Medicine at Mount Sinai, New York, NY, United States

${ }^{3}$ Yale School of Medicine \& Yale New Haven Health, Stratford, CT, United States
}

\section{Corresponding Author:}

Yauheni Solad, MD, MHS

Yale New Haven Health

Digital Health

99 Hawley Lane

Stratford, CT, 06614

United States

Phone: 8633095

Email: yauheni.solad@yale.edu

\section{Abstract}

Background: Patient portals provide a simplified route for health providers to share medical information with individual patients, and are incentivized under Meaningful Use. Currently there are numerous friction factors in the onboarding process of patient portals that limits patients signing up for them. As a result, health systems are spending significant resources to drive the adoption of patient portals, with limited success.

Objective: To evaluate the effectiveness of a innovative rules-driven digital patient engagement strategy for patients to sign up for online patient portal at an academic medical center.

Methods: Rx.Universe is a digital platform integrated into provider EMR systems that enables physicians to directly "prescribe" mobile health applications and/or digital care bundles to patients. Rx.Universe Bulk Prescription feature was used to prescribe-via SMS - a direct link to the MyChart login page with the patient's unique code and personal information embedded within the link. This removed several key barriers to adoption: patients needing to copy and paste access codes, fill in their personal data and complete this process within 30 days-after which their unique access code expires. The Rx.Universe engagement dashboard displayed the total number of patients who received prescribed messages, the number of unsuccessful prescriptions, prescriptions opened in the first 24 hours, and total prescriptions opened.

Results: We digitally prescribed MyChart Activation to 23,485 patients under the care of Yale-New Haven Hospital over a period of 2 days. Of these prescriptions, 21,997 (93.66\%) were successfully delivered and 1488 (6.33\%) failed to be delivered because of incorrect cell phone numbers in EHR. Of the prescriptions successfully prescribed, $2170(9.86 \%)$ were clicked within 24 hours of being prescribed with a total of $2378(10.81 \%)$ clicked within a week.

Conclusions: Digital Medicine Platforms offer new channel for onboarding and following up patients through customized digital care plans. The power of this approach in removing barriers for patients is highlighted by the fact that Yale-New Haven Hospital met their yearly MyChart adoption target through this campaign within a week. Furthermore, the data could be assessed and acted upon in real-time as opposed to the usual weeks. This technology can be extended to close the care gaps for hospitals and Accountable Care Organizations (ACO) in a scalable manner for a subpopulation, with manual processes reserved for patients unable to be reached in an automated fashion.

(iproc 2018;4(2):e11816) doi: 10.2196/11816

\section{KEYWORDS}

patient engagement; platform 
Edited by T Hale; this is a non-peer-reviewed article. Submitted 02.08.18; accepted 29.08.18; published 17.09.18.

Please cite as:

Solad Y, Patel S, Hsiao A, Atreja A

A Novel Digital Platform Approach to Enhance Enterprise-Wide Patient Portal Adoption

iproc 2018;4(2):e11816

URL: http://www.iproc.org/2018/2/e11816/

doi: $\underline{10.2196 / 11816}$

PMID:

(C) Yauheni Solad, Shrawan Patel, Allen Hsiao, Ashish Atreja. Originally published in Iproceedings (http://www.iproc.org), 17.09.2018. This is an open-access article distributed under the terms of the Creative Commons Attribution License (https://creativecommons.org/licenses/by/4.0/), which permits unrestricted use, distribution, and reproduction in any medium, provided the original work, first published in Iproceedings, is properly cited. The complete bibliographic information, a link to the original publication on http://www.iproc.org/, as well as this copyright and license information must be included. 